\title{
UNA MIRADA EN EL MEMENTO MORI \\ DE PARADISO: EL VANITAS Y SU TRANSMISIÓN \\ DEL DESENGAÑO DEL MUNDO
}

\author{
María Del Mar Rodríguez Zárate ${ }^{1}$ \\ Universidad de Monterrey, México
}

\begin{abstract}
Resumen: La experiencia del encuentro sensible con la pieza artística despierta en nuestro espíritu aquello que el artista vio desde su estremecimiento propio. José Lezama Lima toma la pluma como si fuese pincel y traza en el lienzo de su obra Paradiso una poética narrativa que incita nuestra sensibilidad y transmite una textura imaginaria de lo real. La presencia del vanitas en los capítulos primero y séptimo no busca evocar una simple imagen sino estimular más allá del reconocimiento intelectual de dicha apariencia plástica. La vida como vanidad, el memento mori, transita como temática en estos cuadros descriptivos; transmite el mensaje del desengaño del mundo y toca nuestras fibras más hondas y humanas.
\end{abstract}

Palabras claves: Arte; filosofía; memento mori; Paradiso; vanitas.

Recibido: 10 de marzo de 2018

Aprobado: 3 de abril de 2018

A LOOK AT THE MEMENTO MORI OF PARADISO: THE VANITAS AND ITS TRANSMISSION OF THE DISAPPOINTMENT OF THE WORLD

Abstract: When we experience a sensitive encounter with an artistic piece, the accuracy of what the artist saw from his own tremor is awakened in the depths of our spirit. José Lezama Lima takes the pen as if it was a brush and draws on the canvas of his work Paradiso a poetic narrative that incites our sensibility. The presence of a vanitas in the first and seventh chapters stimulates us beyond the intellectual recognition of this plastic appearance. The theme of life as vanity, the memento mori that comes with this vanitas, is transmitted as a messa-

${ }^{1}$ María del Mar Rodríguez-Zárate cursa actualmente la Licenciatura en Letras en la Universidad de Monterrey. Sus áreas de investigación comprenden literatura, arte y estética. Publicó en 2016 el artículo titulado "Por qué enamorarse del hilo extraviado de una cabellera rubia: El valor de la literatura grecolatina en nuestros tiempos" en la Revista Grama $22^{\circ}$ y participó en la ceremonia de develación de placa del Premio Alfonso Reyes en honor a Sergio Pitol, con ponencia titulada "Las máscaras sociales y axiomáticas en la narrativa de Sergio Pitol". Correo electrónico: maria.rodriguezz@udem.edu.co 
ge of the disappointment of the world, touching our deepest and most human fibers.

Keywords: Art; memento mori; Paradiso; philosophy; vanitas.

\section{Introducción}

La visión no es un mero acto de observación. Siendo seres sensibles, contamos con una mirada interna que apela a nuestra capacidad emotiva y artística. Así, el encuentro con la obra de arte entabla un diálogo profundo con nuestra corporalidad que, a través de la experiencia que brinda el encuentro sensible con la pieza artística, recrea -en nuestro espíritu - la exactitud, aquello que el artista vio desde su estremecimiento propio. Como establece Merleau-Ponty (1986), “el cuadro más que un análogo conforme al cuerpo no ofrece al espíritu una ocasión de repensar las relaciones constitutivas de las cosas, sino a la mirada las trazas de la visión de adentro para que las posea, y a la visión lo que la tapiza interiormente, o sea la textura imaginaria de lo real" (20); el arte no busca la recreación ni la mimesis de lo sensitivo, sino producir en la materialidad aquello que despierta la imaginación de lo real, lo más interior de la visión y no la observación en sí misma.

Lezama Lima toma la pluma como si fuese pincel y traza en el lienzo de su obra Paradiso una poética narrativa que incita nuestra sensibilidad y transmite, desde sus simbologías y referencias, una textura imaginaria de lo real. Por tanto, la plasticidad, elemento inmerso en las intertextualidades y parte de las obsesiones del autor, no se manifiesta meramente en la écfrasis o la mención de obras y pintores sino que busca ir más lejos y tornarse en un "juego de imaginación" (Vilaltella 89).

La presencia del vanitas en los capítulos I y VII, por ejemplo, no busca fijar una imagen desde la cognición sino estimularnos más allá del reconocimiento intelectual de dicha apariencia plástica. La vida como vanidad, el memento mori, suscita la iconografía de lo efímero en la naturaleza muerta, transita entre las líneas y descripciones de objetos, alimentos y espacios oscuros. Desde su presentación, como obra plástica-literaria visible y vidente, capta el imaginario del escritorartista para que, desde el sensualismo, el mensaje del desengaño del 
mundo toque las fibras más hondas y humanas del lector convertido en espectador.

La presente investigación tiene como objetivo analizar la forma de transmisión del tópico del memento mori presente en los capítulos I y VII de Paradiso, mediante el vanitas según la filosofía del arte de MerleauPonty. Tiene como objetivo dilucidar el rol que tiene la observación del lector, convertido ahora en espectador del pintor/escritor, apelando a su corporalidad para la comunicación del desengaño del mundo - temática oculta que transita la plasticidad simbólica de la obra. La relevancia del estudio consiste en que, al ampliar la concepción de naturaleza muerta en los capítulos I y VII, se estudiará a detalle su presencia y carácter de vanitas; que solo ha sido nombrado — de forma tangencial— como bodegón por académicos como: Carolina Toledo, Ana Porrúa y Edelmira Gonzáles. De esta forma, se constatará la presencia de la temática del desengaño (memento mori) en la obra, como un nivel simbólico que suscita el vanitas y que, desde la teoría filosófica del arte de MerleauPonty, brindará una perspectiva distinta que devele un mecanismo literario-plástico para la transmisión de la idea del memento mori que el artista $^{2}$ apela en la corporalidad del espectador. La metodología será el análisis plástico y simbólico, desde la definición de vanitas ${ }^{3}$, y las reflexiones artístico-filosóficas de Merleau-Ponty en el capítulo II de El ojo y el espíritu.

\section{Arquetipos de la cotidianidad: la presencia del bodegón en el capí- tulo I y VII de Paradiso}

La manifestación de referencias propias a diversas pinturas canónicas en Paradiso es muestra de la evidente preocupación y obsesión plástica que acompañó Lezama Lima en su producción poética y narrativa. Como establece Vilaltella, "si uno toma el conjunto de los ensayos de Lezama, no cabe duda de que la pintura constituye una de sus preocupaciones críticas importantes" (88), siendo posible, desde su concepción, evidenciar alrededor de treinta y cinco (35) pinturas

\footnotetext{
${ }^{2}$ Entiéndase artista en el sentido amplio de la palabra y no sólo en la plasticidad.

3 "pertenece al género que los historiadores del arte entienden como vanitas, ya que está concebida como una advertencia sobre la vanidad de la vida terrena, un memento mori. Su visualidad se fundamenta en una retórica que desde la baja Edad Media llegó a convertirse en un tópico de dicho tema: la calavera descarnada como icono de la muerte" (Vives Ferrándiz Sánchez 13,14)
} 
y cuarenta y seis (46) referencias a lo largo de la novela. Mediante reproducciones, libros y láminas, Lezama se acerca al arte internacional no de la forma anhelada — la observación directa del original — sino desde la copia. Impulso que, si bien resultó un inconveniente para el acto de apreciación, "esta dificultad práctica — apreciar el arte a través de reproducciones - [...] no fue un impedimento para que Lezama hiciera sobre muchas obras de arte interesantes críticas" (Acosta de Arriba 11), terminó por incitar su capacidad reflexiva, interpretativa e imaginativa en los laberintos poéticos y simbólicos de Paradiso.

Por tal motivo, la búsqueda por reconocer las posibilidades ecfrásticas, así como alusiones pictóricas yacentes en el texto y sus posibles connotaciones, es tangencialmente mencionada por autores como Carolina Toledo, Ana Porrúa y Edelmira Gonzáles. Ellas han señalado la presencia del bodegón como elemento plástico patente en la obra, que va más allá de las referencias ya establecidas y reconocidas como intertextualidades. En cuanto al bodegón del capítulo I, Toledo argumenta que la relación entre los conocimientos plásticos locales de Lezama y su estrecha relación con Amelia Peláez podría explicar la descripción de las comidas del gossá familia que aluden a "un tratamiento peculiar del bodegón no solamente a través de símiles o alusiones directas — como la citada anteriormente para indicar la sencillez de la casa - sino además por las escenas que describen las comidas familiares" (Toledo 5,6) haciendo posible su reminiscencia con el Bodegón con membrillo, repollo, melón y pepino de Juan Sánchez Cotán, obra que Lezama conoció de forma directa ${ }^{4}$. Asimismo, Edelmira Gonzáles en su exploración espacial de la obra, centrándose en el aspecto de la casa del Coronel en el primer capítulo, como lugar donde convive lo animado e inanimado, menciona:

Allí están las pertenencias significativas del Jefe, 'naturalezas muertas': las mesas de trabajo donde había labores de ingeniero, el juego de Yaqui $[s i c]$ con pelotas de tripa de pato, y otros objetos. Pero son los

\footnotetext{
${ }^{4}$ Como posiblemente busca constatar Acosta de Riba: "Para José Lezama Lima fue en sumo importante detenerse delante de un cuadro de fray Sánchez Cotán, traído al Museo de Bellas Artes de La Habana por la French Gallery en marzo de 1958. La obra, vista por él antes en un catálogo, lo había impresionado de tal manera que escribió entonces el texto "El bodegón prodigioso", incluido más tarde en su libro de ensayos Tratados en La Habana" (11)
} 
libros en los estantes, por su contenido y la posición como están colocados los objetos que nos dan la clave sobre la personalidad del Jefe, sus costumbres, su cultura (Gonzáles Maldonado 2018 94).

Lo anterior reitera la presencia de una temática propia de la naturaleza muerta en la mención del escritorio y pertenencias del Coronel, mismas que conviven con la descripción de la cocina: "—-pintada a trazos como un bodegón de tonos oscuros - es el lugar en que el mulato Izquierdo "oficia" con todos los embrujos de las especies y las miles que informan su arte" (Gonzáles Maldonado 95) evidenciando, consecuentemente, la convivencia de objetos naturales (platillos, postres, melón) y artificiales (libros, sombreros, labores de ingeniero) como íconos característicos de la plasticidad del bodegón.

Sobre una posible naturaleza muerta en el capítulo VII, menciona la autora Ana Porrúa que el episodio correspondiente a la cena de doña Augusta puede ser visto como lienzo de una posible plasticidad:

El bodegón de Lezama Lima - uso aquí los términos de manera intercambiable - trae los signos de la abundancia, colores, frutos, langostinos, pero además el componente descriptivo también juega a saturar la presentación de la escena. La saturación es contraria a la abstracción y la nitidez; los colores se usan para abrir una paleta y no para distinguir planos u objetos. El soporte no es nítido, sino que está cubierto por el artificio de la naturaleza, a modo de ornamento: 'los colores de las frutas se mostraban por 'variados listones entrelazados', leemos en el fragmento y estas se transforman en orla del 'plato con bordes curvos' montado en un pie de cristal. El langostino, por su parte, se hace visible en el summun [sic] de la pose, simulando el ascenso desde el extremo inferior de la frutera (toda una performance) (Porrúa 10).

Si a estos bodegones narrativos sumamos la presencia de la muerte, desde los símbolos iconográficos que rondan ambos episodios, se puede constatar que se trata de un carácter más específico de naturaleza muerta conocida como vanitas que "está concebida como una advertencia sobre la vanidad de la vida terrena, un memento mori $[\ldots]$ muestra de un tipo iconográfico desarrollado a partir del siglo XVI y que conoce un impulso renovado dentro de la cultura del barroco" (Vives Ferrándiz Sánchez 13,14) lo que confirma, consecuentemente, la transmisión del 
mensaje de desengaño del mundo (memento mori) desde la simbología de sus íconos. Sin embargo, el presente estudio no solo se distinguirá por esgrimir dicho aspecto delimitado con respecto a los aquí citados, sino que, además, tomará en cuenta el cómo de la transmisión de dicha temática del desengaño mediante el vanitas, siendo el tratamiento de Lezama uno de carácter distinto a la simple écfrasis y que se aproxima a la concepción filosófica y estética de Merleau-Ponty.

\section{Cuando la muerte asoma por el bodegón: el carácter de vanitas en} la iconografía de la muerte y la temática del memento mori.

Mirar, acto de total sensibilidad, implica corroborar nuestro existir. Las indagaciones más ontológicas y espirituales del ser humano se materializan en los fenómenos circundantes, tornándose de pronto en realidades cercanas. De esta forma, todo lo que nace, crece y decae nos recuerda la brevedad de nuestra condición ineludiblemente mortal. Solo basta un miramiento contemplativo, reflexivo y sensitivo para corroborarlo. Presunción que, en el arte, poiesis sensible y humana, nos empuja a cobrar conciencia del entorno más allá del transitar superficial de la cotidianidad. Por ello, el artista recrea - mediante la palabra o la plasticidad - íconos expresivos y significantes de su propia observación, consiguiendo obligar a su espectador a detenerse frente a la obra y a poner los ojos en la existencia, bajo la reflexión de sus sensaciones más primigenias, despertando la espiritualidad que lo enlaza con su humanidad.

Cuando Lezama Lima se detiene frente al Bodegón con membrillo, repollo, melón y pepino (1602) de fray Juan Sánchez Cotán, “traída al Museo de Bellas Artes de La Habana por la French Gallery en marzo de 1958" (Acosta de Arriba 11), le es posible contemplar cómo su mirada se funde en la de aquél que plasmó su visión en la obra plástica. Lezama Lima logra aprehender de la obra que "sus elementos de composición nacen de la reiterada contemplación, de esas formas que contempladas todos los días llegan a brindarnos su nacimiento costumbroso, su engallada sorpresa liberada de toda incandescencia" (Gonzáles Maldonado 1996 72), buscando mediante el lirismo que suscita su narrativa la recreación de dicho encuentro, a través de la construcción de un entorno de desbordante connotación simbólica y plástica. 
Es por ello posible apreciar la representación de la naturaleza muerta o bodegón ${ }^{5}$ como parte del imaginario visual que Lezama introduce a lo largo de Paradiso como constata Edelmira Gonzáles ${ }^{6}$. Ciertas descripciones del capítulo I evocan en la imaginación del lector una plasticidad que recuerda a la iconografía y objetivo pictórico de la naturaleza muerta cuando, por ejemplo, se describen las pertenencias del Coronel en su cuarto de estudio: "los libros del Coronel: La Enciclopedia Británica, las obras de Felipe Trigo, novelas de espionaje de la Segunda Guerra Mundial [...] sobre el pupitre, cogidos con alcayatas ya oxidadas, papeles [...] también, formando torres, las cajas con los sombreros de estación de Rialta" (Lezama Lima 111,112) como representaciones arquetípicas de objetos procedentes de la cotidianidad. Asimismo, Carolina Toledo destaca la presencia de elementos plásticos que rememoran al bodegón, no solo en la posible écfrasis del cuadro de Sánchez Cotán, cuando se hace alusión al melón que carga consigo el Coronel (Id. 123), sino también cuando éste recuerda las fastuosas comidas organizadas por su padre en el gossá familia: "en silencio iba allegando delicias de confitados y almendras, de jamones al salmanticense modo, frutas, la que la estación consignaba, pastas austriacas, licores extraídos de las ruinas pompeyanas, convertidos ya en sirope" (Id. 125), donde los platillos y confites hacen alusiones a los placeres de la comida y bebida que circundan la vida del hombre.

Ana Porrúa destaca las descripciones del capítulo VII que aluden al banquete de doña Augusta como posible bodegón, ya que la mantelería "la calidad excepcional se brinda en el mantel de encaje, en la vajilla de un redondel verde por los filetes dorados" (Lezama Lima 322); los platillos, "una pasta de camarones gigantomas [...] formaba parte también del souflé el pescado llamado emperador, que doña Augusta solo empleaba en el cansancio del pargo, cuya masa se había extendido primero por círculos y después por hebras; langostas que mostraban el asombro cárdeno" (Id. 324); y, finalmente, las frutas "el frutero se había colocado al centro de la mesa, sobre una de las manchas de remolacha"

\footnotetext{
${ }^{5}$ Bodegón, sinónimo de naturaleza muerta, definido por el DLE como: "Composición pictórica que expone como tema principal frutas, verdura, caza, pesca, etc., y objetos domésticos diversos."

${ }^{6}$ Citada anteriormente en el apartado de este trabajo Arquetipos de la cotidianidad: la presencia del bodegón en el capítulo I y VII de Paradiso, junto con Ana Porrúa y Carolina Toledo.
} 
(Id. 326); rememoran, como en el capítulo I, la belleza de los placeres que suscitan la comida y bebida.

Sin embargo, dentro de esta plasticidad, que evoca la celebración vital y placentera del hombre, elementos ajenos y contrastantes circundan alrededor de las detalladas y evocadoras descripciones lezamianas. Si nuestra mirada se torna contemplativa, más allá del paladeo de la belleza despertada en los pasajes anteriores, es posible observar que la muerte se asoma a estos festines llenos de color, sabor y alegría desde una simbología e iconografía que funge como un recuerdo de su fugacidad y fragilidad. Esta reminiscencia apela, por tanto, a una intencionalidad figurativa que no pertenece al carácter de bodegón. Como señala Osvaldo Svanscini "las naturalezas muertas o los bodegones no incluyen metáforas que escondan una intención literaria: son simplemente arquetipos de lo frecuente, y al erigirse como tema principal desafían las preferencias habituales" (7) lo que no corresponde con la temática que circunda discretamente las descripciones vislumbradas con anterioridad.

Existe un género pictórico que deriva del bodegón que sí genera una connotación más allá de la representación de la cotidianidad y sus delectaciones. El vanitas, que "ha sido estudiada, tradicionalmente, como un tema, subtema o género dentro de un tema mayor en el que se engloba: la pintura de naturaleza muerta" (Vives Ferrándiz Sánchez 21), añade un tópico tomado de las palabras de Salomón en el Eclesiastés: Vanitas vanitatum omnia vanitas. Esto genera que su iconografía, entre la cuál destacan elementos como "un esqueleto o una calavera, flores, hortalizas, velas, relojes, burbujas, joyas, etc" (Stecher, Suzzi y Krasel 6), adquiera un carácter simbólico que refleje la vanidad de la vida terrena; un memento mori, que conduce al espectador a la angustia y la contemplación de la muerte como algo ineludible. Por tanto, las riquezas y los placeres - de gran goce en las representaciones de naturalezas muertas - se suman a pequeños guiños simbólicos e iconográficos que remiten a la fragilidad, el paso del tiempo y finalmente a la muerte. Misma "con la cual el espectador puede identificarse, porque esa calavera podría ser la suya propia" (Ibid. 6), adquiriendo un nivel significativo y metafórico que desengaña al hombre, al mostrarle sus placeres y creaciones, como vanidades frente a su finitud existencial. 
En el capítulo I, los íconos de la fragilidad de la vida que demuestran el carácter del vanitas se manifiestan primeramente en la vela del candelabro de Baldovina: "logró encender la vela del candelabro" (Lezama Lima 113), símbolo de una vida que puede apagarse en un soplo, de una luz que tarde o temprano caerá en las sombras de la inexistencia. La plasticidad evocada en dicha alusión nos remite a la "la atmosfera de las pinturas [vanitas], la mayoría con fondos oscuros y un tanto 'teatrales' llevan a el verdadero recordatorio de la muerte" (Stecher, Suzzi y Krasel 6); puesto que la penumbra de ese teatro nocturno (Lezama Lima 110) y la débil luz generada por la nana de la casa, generarán una confrontación frente a las descripciones posteriores de frutas, platillos y objetos abundantemente gustosos, remitiendo a la inestabilidad de la existencia. Así, lo hace otro ícono inmerso en el bodegón que es observable en la presentación de los objetos del estudio del Coronel, donde hace aparición una flor muerta, en el ave de paraíso de Rialta: "trasladada de un sombrero a otro, pareciéndonos así que aquella ave disecada volvía a agitarse en el aire" (Id. 112); lo que suscita un recordatorio del decaimiento y la degradación, procesos naturales de la vida y de los objetos en sí mismos. Nada dura para siempre, todo cumple un ciclo vital donde la expiración es inminente.

El capítulo I suscita tres premoniciones donde la "calavera" o la muerte misma, ronda los goces familiares y la vivacidad de sus entornos. La enfermedad, señal de decaimiento y claro recordatorio de nuestra condición frágil, es vista desde un inicio con el personaje de Cemí, a quien se le describe: "decía cuerpo y las ronchas, como si los viera crecer siempre o como si lentamente su espiral de plancha movida, de incorrecta gelatina, viera la aparición fantasmal y rosada, la emigración de esas nubes sobre el pequeño cuerpo" (Lezama Lima 109), constatando la cercanía del pequeño con la muerte, siendo un cuerpo que se debate violentamente frente a las ronchas y la falta de aire cada vez mayor. Así, pese a que libra a la calavera, puesto que "el muchacho estaba vivo por puro y sencillo milagro" (Id. 117); se advierte la presencia de la muerte en el pequeño, contrastando fuertemente con las vívidas alusiones de bodegones y festines. El melón del Coronel, elemento de abundancia al describir la extracción de la "mogolla" comparte con la muerte un 
momento de revelación: "los treinta y tres años que alcanzó su vida fueron de una alegre severidad, parecía que empujaba a su esposa y a sus tres hijos por los vericuetos de su sangre resuelta" (Id. 123); con lo cual constata, paradójicamente, la edad exacta en que el Coronel dejará de existir, mientras observamos en la plenitud de la vida y con uno de sus más grandes gustos: el melón que lleva bajo el brazo. Vida y muerte conviven como uno solo, nos hacen mirar en un Coronel alegre y jovial, la calavera que ya asoma su melón vaciado. Finalmente, el recuerdo de su padre, el fallecido vasco, trae consigo a nuestra memoria los tiempos felices del ayer, "no perdió nunca la fortaleza, buena señal de que estaba taponado por Dios" (Id. 126); evocando un tiempo finiquitado por la presencia la muerte.

En el capítulo VII, un ícono que nos hace vislumbrar la inestabilidad de lo mundano se da en la mención de los camarones de la cena. Se relata que "al sentir la cercanía de la muerte, se abandona a la corriente que lo lleva a ciertas profundidades rocosas, donde se adhiere bien para morir" (Lezama Lima 324); alimento que refleja, más allá de su deleite y paladeo descriptivo, un reflejo oscuro y cadavérico que le acompaña. Asimismo, la mantelería de la cena, de gran belleza y esplendor para la vista, trae consigo un recuerdo del pasado que nos rememora el transitar del tiempo y los seres perdidos: "a la muerte de Cambita, la hija del oidor, ese mantel que recordaba la época de las gorgueras y de las walonas, había pasado a poder de doña Augusta" (Id. 322), volviendo a generar, como en la suntuosidad oscura de los camarones, un contraste entre la vida y la muerte que trae a nuestra mirada la inminente fragilidad y decaimiento de la existencia. Por ello, al hacer aparición la calavera en sí misma, "las parcas ahora podían tejer con un suave ocio voluptuoso" (Id. 329), hemos ajustado nuestra mirada a la convivencia ineludible del transitar existencial de la mano con la certeza de la finitud, por lo que la frase puede pasar desapercibida, pero potente en la transmisión del memento mori.

Como en el capítulo I, tres son las alusiones a la "calavera" que nos remiten a confrontar los placeres de la cena de Augusta desde una contemplación desengañada. Durante el banquete, la enfermedad hace aparición constantemente como temática de conversación "- $-\mathrm{Se}$ 
desconoce en realidad el origen de esa enfermedad - dijo Santurce, que como médico no sentía la impropiedad de hablar de cualquier enfermedad a la hora de la comida" (Lezama Lima 325), tópico contrastante dentro de este cuadro que parece celebrar la abundancia y el deleite de múltiples platillos, así como la armonía familiar. No obstante, como una cuestión premonitoria, al terminar el festín, el Doctor Santurce anuncia a Alberto la enfermedad de su madre "ella le daba esa alegría de sentirse seguro y aún joven, pues en realidad la vejez de un hombre comienza el día de la muerte de su madre" (Id. 328); sellando con esto no solo la proximidad de doña Augusta a su partida terrenal, sino la de su propio hijo, quien ahora comienza a sentirse viejo y cercano a las parcas, que ya entretejen su destino (Id. 329). Así, Alberto no imagina que, en esta contemplación del memento mori bajo el temor de la pérdida, le tocará adelantarse a su madre; siendo la música, ícono de un placer fugaz y efímero, la que lo acompaña durante su último trayecto: "La muerte me está buscando, y como me puse serio, me dijo que era jugando, pero la muerte sigue buscando" (Id. 332); llevándose a un personaje, de gran vitalidad en la novela, de una manera inesperada y haciéndonos contemplar que la fragilidad de la vida es nuestro común denominador, efectuándose el fin como el breve sonido de un acorde.

Así, es posible vislumbrar que, más allá del deleite de la vida, sus placeres y objetos presentes en ambos capítulos, la muerte asoma por sus bodegones. El carácter de vanitas y el memento mori, que se consolida en su iconografía simbólica, cambian la mirada en torno a la plasticidad que Lezama Lima evoca en los pasajes estudiados. Lo efímero, la fragilidad y la mortalidad se transmiten como parte del mensaje metafórico que el vanitas suscita en la poética narrativa lezamiana, evocando una mirada reflexiva en el lienzo imaginativo del lector.

\section{El ojo de Lezama en sus letras pinceladas: la forma de transmisión de la temática del desengaño del mundo}

La vista ha sido considerada como el más noble de los sentidos, establece el vínculo entre las conceptualizaciones del mundo y la información proporcionada por el resto de las aproximaciones 
sensoriales. El ojo es el órgano de mayor percepción puesto que nos hace despertar a las verdades que nos circundan de forma profunda e inmediata. Así lo señala Maurice Merleau-Ponty, para quien la obra de arte no rehúye a este rol trascendental de la mirada y las conexiones que suscita con el espíritu. El cuerpo, la sensación más primigenia, precede a todo intelectualismo; por lo que: "es prestando su cuerpo al mundo que el pintor cambia el mundo en pintura" (Merleau-Ponty 15), siendo su mirada una traducción de la experiencia fenomenológica, del encuentro particular que sostiene el artista con el entorno. Por ello, el pintor solo se acerca a una transmisión de su sentir más íntimo mediante la contemplación, se abre al contexto para plasmar de éste la maduración de su visión. No obstante, siendo que las cosas del mundo son constituidas al igual que la corporalidad del hombre, "es necesario que su visión [la del pintor] se haga de alguna manera en ellos, que su visibilidad manifiesta se duplique con una visibilidad secreta" (Id. 16); misma que puede canalizarse en la materialidad de la obra de arte, que es - a la vez - visible en sí, haciendo posible que otra mirada pueda encontrar la introspección que sostuvo el artista en su encuentro sensitivo con el mundo.

La obra de arte involucra la participación de tres ojos en torno al despertar de una verdad que irradia lo más íntimo del espíritu: el artista que mira; la plasticidad, que plasma la visión del pintor haciéndola visible al otro; y, finalmente, el que mira e interioriza la conexión de la contemplación del pintor con la suya propia. El arte vincula dos espiritualidades en relación con una materialidad que abre los ojos a la comprensión, a la visión íntima que busca develar la transmisión particular de la percepción. Por tanto, como señala Merleau-Ponty, las obras artísticas no pueden ser un mero duplicado débil de las cosas porque "son el adentro del afuera y el afuera del adentro, que hacen posible la duplicidad del sentir, y sin los cuales nunca se comprenderá la casi-presencia y la visibilidad inminente que constituyen todo el problema de lo imaginario" (Merleau-Ponty 20); lo que permite remitirnos a los bosquejos de la mirada interior, a la textura imaginaria de lo real. Asimismo, la manera en que se da la conmoción que provoca el encuentro con la obra de arte y su posterior transmisión al otro 
requiere necesariamente del ojo: "eso que se ha conmovido por cierto impacto del mundo y lo restituye a lo visible por los trazos de la mano" (Id. 21), puesto que la pintura despierta el encuentro de una visión que otorga mensajes sensoriales del ser.

La mirada es, en definitiva, el instrumento para el desengaño del hombre; el recurso que el vanitas, en su iconografía simbólica, emplea para moldear una visión que se dirija "al tiempo, al instante presente y al momento pasado, para reconocer en cada dimensión el retrato que compone su calavera. [...] enseña a mirar la representación de la vida humana, como una obra de teatro o como un lienzo, para descubrir el punto de vista óptimo que descubre su condición engañosa" (Vives Ferrándiz Sánchez 17), contemplación que busca suscitar en el espectador una verdad desde su experiencia más corporal. Así, en la inmediatez que suscita la mirada, nociones como el paso del tiempo y el decaimiento inevitable de nuestra condición efímera adquieren una toma de conciencia de gran peso. La conmoción de los elementos iconográficos, el estremecimiento que producen sus simbologías mediante la vinculación de las visiones, desengañan al espectador y le obligan a voltear la mirada entorno a la contemplación e interiorización del memento mori. Así, "el desengaño reduce la vida a un breve lapso, comprimiendo el tiempo con la mirada al juntar el momento del nacer con el del morir" (Id. 38), donde observamos que la fertilidad y la abundancia de los placeres del bodegón quedan constantemente adheridos a la inevitable fragilidad que desprende del memento mori.

Lezama Lima recurre a la palabra como pincel y traza los vanitas que circundan el capítulo I y VII; siendo el lienzo narrativo de Paradiso, mediante la elocuencia de sus descripciones y la presencia de la muerte, uno que evoca la textura imaginaria de una obra plástica. Así, la forma de transmisión del memento mori, este desengaño del mundo que nos hace interiorizar y aceptar nuestra inmanencia con lo perecedero, llega a transmitirse al lector mediante el sutil instrumento que elimina las apariencias de lo mundano: la mirada. La percepción reflexiva de Lezama Lima, bajo su propia conmoción frente a numerosas obras plásticas y su preocupación estético- - temática por la muerte, se recrea en la palabra y traza visualizaciones detalladas de elementos vitales en 
convivencia con su decaimiento. El lector imagina, gracias al impulso de la descripción poética y visual, la obra plástica en el lienzo de su mente y contempla un cuadro único e íntimo que se suma a la visión del autor. Bajo dicha corporalización imaginaria del relato, el lector aprehende que, más allá de las celebraciones familiares, los platillos y los objetos personales, el paso del tiempo, la fugacidad y el desfallecimiento son tan propios de los personajes como de él mismo. Escritor y lector se suman en una mirada que recrea y percibe la sensación de aquello tan visible como invisible, tan imaginario como real; contemplación que despliega "significaciones mudas" (Merleau-Ponty 28) develando nuestra esencia y existencia tal cuál es: frágil y efímera.

La figura de Lezama Lima se torna en la del pintor de la palabra, mismo que vive en la fascinación, siendo "sus acciones más características — esos gestos, esos trazados de los que solo él es capaz, y que serán revelación para los otros porque no tienen las mismas carencias que él- [lo que] al pintor le parece que emanan de las cosas mismas" (Merleau-Ponty 24); por lo cual Lezama Lima mira, en su encuentro con el entorno, la esencia del ser humano y genera un canal que haga visible su experiencia, que nos transmita su conmoción y las verdades que de ella emanan. Dicho conducto debe mostrar lo invisible de la sensación siendo en simultaneidad visible para el otro, consolidación que el autor logra incluso de forma más potente que un pintor. La palabra es un ente material que puede ser tan observado como la pintura. Pero, su poder evocativo, estremece al lector haciéndole formular por él mismo la imagen descrita; visión que se torna única en su mente y que suscita un cuadro tan invisible como visible, mismo que atañe a lo más íntimo de su experiencia con el texto. Somos nosotros, los lectores, quienes observamos estos vanitas imaginarios que Lezama contempló en su propia conmoción; mas, generando una obra "talismán del mundo, para hacernos ver lo visible" (Id. 23), única, íntima e irrepetible.

Dicha contemplación interior, que nos suma con la mirada del escritor-pintor en torno al vanitas imaginario, nos torna en espectadores de una obra que doblemente nos conmueve: la palabra genera un estremecimiento imaginativo y el producto de esto nos devela lo que el artista vio desde su conmoción particular. La representación 
plástica, que nos hermana en torno a las descripciones narrativas de los vanitas de Paradiso, nos hace abrir los ojos a que "si todo es apariencia, tanto en el mundo como en el hombre, la mirada debe dirigirse hacia el interior en un ejercicio de introspección para aprender, de nuevo, que el hombre es mortal" (Vives Ferrándiz Sánchez 29), revelación que nos hace adquirir una conciencia interna del memento mori que busca transmitir el vanitas. No obstante, a diferencia de la plástica que demanda un mirar físico y posteriormente un mirar interno, este despertar y recordar se da desde un inicio en el espíritu, porque la materialidad plástica yace en él, en la imaginación evocada. Por tanto, el rol del lector se torna en el de un espectador, capaz de ver en la representación de la palabra y su imaginación, no solo la visión del escritor-pintor, sino la esencia mortal del hombre que el vanitas busca transmitirle; quedando desengañado de su pretensión inmortal y tomando conciencia de la condición efímera que circunscribe a todo objeto natural. De esta forma, la contemplación a la que apela el vanitas, como instrumento para el recordatorio de nuestro estado perecedero, logra concretarse en el impulso imaginativo que suscitan los pasajes estudiados; ya que, nuestra sensibilidad, conmovida por el encuentro con la palabra y la imagen que ésta fórmula en nuestro interior, es capaz de aprehender como lectores - espectadores una visión que abre nuestros ojos a la esencia del ser.

La forma en que se transmite la temática del memento mori - que emana de la presencia del vanitas en Paradiso-, genera un juego contemplativo donde "la visión del pintor es un nacimiento continuado" (Merleau-Ponty 25) que habita innumerables veces el lienzo de nuestra imaginación, sumándola a la conmoción del mismo Lezama Lima. Se trata de un cuadro, texturizado por nuestra visión sensorial y mental, que se vuelve capaz de develar un recordatorio latente de la condición mortal que nos atañe desde lo más íntimo de nuestro espíritu. Lo que buscamos hacer invisible en nuestro transitar existencial, se presenta ante nuestros ojos como una verdad notoria e ineludible: cabe el instante de un parpadeo para que, lo que hoy contemplamos, perezca. 


\section{Conclusión}

Cuando se trata de la muerte solemos ver más no miramos. Nada se esconde cuando el carácter de la observación es contemplativo e involucra al espíritu. En dicha conexión, no es posible huir de aquello que se torna inminente frente a nuestros ojos; puesto que, en ello, se consolida un diálogo profundo con las fibras más íntimas que nos constituyen como entes sensibles. La vista, por tanto, es el órgano de mayor nobleza cuando se trata de aproximarnos al entorno. Pero, la mirada supera este simple vínculo: es nuestro enlace con los fenómenos sensitivos de la realidad, con la develación de su esencia. De esta forma, la existencia adquiere otro sentido para quien la contempla, acto capaz de rememorar la verdad que yace más allá de la mera superficie de la percepción.

La obra de arte surge como un medio a través del cual se logra comunicar la experiencia trascendental de la contemplación, convirtiéndola en un ente visible a través de la materialidad artística. Así, ésta entabla un diálogo profundo con nuestra corporalidad ya que, a través del encuentro sensible con la pieza artística, se recrea en nuestro espíritu la exactitud de lo que el artista vio desde su estremecimiento propio. La plasticidad del vanitas, mediante su iconografía de carácter simbólico, logra evocar un memento mori que nos exige ir más allá de la simple vista, para mirar la presencia inminente de la muerte en nuestro entorno. Por tanto, el vanitas conecta al ojo con el espíritu del artista y del espectador en relación con una materialidad, misma que es capaz de develar una de las verdades más rehuidas de nuestro transitar por la vida: la fragilidad de nuestra condición mortal. Por ende, su presencia en los capítulos I y VII de Paradiso, no busca hacernos ver una imagen bellamente descriptiva, sino estimularnos más allá del reconocimiento intelectual de dicha apariencia plástica.

Lezama Lima toma la pluma como si fuese pincel y traza en el lienzo de su obra Paradiso una poética narrativa, una textura imaginaria de lo real; donde la vida como vanidad, el memento mori, transita entre las líneas y descripciones de objetos, alimentos y espacios oscuros. La forma en que se transmite dicha temática genera un juego contemplativo donde, como lectores, debemos ser espectadores de 
aquello que buscaba hacer visible el escritor-pintor. De esta forma, la conmoción e imaginación visual del propio Lezama se recrea en la intimidad del lector, en una plasticidad que yace en su mente de forma potente y personal que marca lo más profundo de su espíritu y dirige su mirada al recordatorio visible y vidente de la muerte, al desengaño del mundo. Porque la calavera coexiste en la abundancia de nuestros banquetes y platillos, como lo hace para el Coronel y doña Augusta; porque las cosas desaparecen y desfallecen, como nuestra existencia misma. Nada de lo que atañe al hombre es eterno, aunque éste pretenda vivir como si su vida transcurriese en la inmortalidad.

Así, esta mirada que devela la esencia humana, verdad tan invisible como vidente de la conmoción que suscita nuestro encuentro con la plasticidad de la palabra, nos deja — como la impresión que Mamita tiene del Coronel - un mensaje que debemos asimilar: "la muerte siempre estaba tan cerca de él, que no había por qué temerle" (Lezama Lima 142).

\section{Referencias}

Acosta de Arriba, Rafael. «Los ojos minervinos de Lezama Lima.» Revista de la Biblioteca Nacional José Martí (2010): 11-21. Digital.

Gonzáles Maldonado, Edelmira. «Dos intentos de interpretación de Lezama Lima.» Revista Educación Universidad Interamericana de Puerto Rico (2018): 91-95. Digital.

Gonzáles Maldonado, Edelmira. «El Bodegón Prodigioso.» Lezama Lima, José. La Materia Atizada (Críticas De Arte). Madrid: Editorial Técnos, 1996. 71-73. Impreso.

Lezama Lima, José. Paradiso. Madrid: Cátedra, 2017. Impreso .

Merleau Ponty, Maurice. «II.» Merleau Ponty, Maurice. El ojo y el espiritu. Buenos Aires: Paidós, 1986. Impreso .

Porrúa, Ana. «Naturaleza muerta/Naturaleza o muerte.» IV Congreso Internacional Cuestiones Críticas. Buenos Aires: Facultad de Humanidades y Artes, Universidad del Rosario, 2015. Digital.

Stecher, Mariana, Ana Laura Suzzi y Mariana Krasel. «La muerte como vanidad.» II Jornadas Estudiantiles de Investigación en Disciplinas Artísticas y Proyectuales. La Plata: Facultad de Bellas Artes, Universidad La Plata, 2016. Digital. 
Svanascin, Osvaldo. Bodegones. Buenos Aires: Pontificia Universidad Católica Argentina Pabellón De Las Bellas Artes, 2007. Digital.

Toledo, Carolina. «La perspectiva plástica en Paradiso de José Lezama Lima.» VIII Congreso Internacional Orbis Tertius de Teoría y Crítica Literaria. La Plata, Argentina: Facultad de Humanidades y Ciencias de la Educación, Universidad Nacional La Plata, 2012. Digital.

Vilaltella, Javier. «Escritura-pintura y reproducciones en Lezama Lima.» Revista de crítica literaria latinoamericana (2002): 87-91. Digital.

Vives Ferrándiz Sánchez, Luis. Vanitas: Retórica visual de la mirada. Madrid: Encuentro, 2011. Impreso. 